\title{
Homeworking Project Management \& Agility as the New Normal in a Covid-19 World
}

\author{
Patcharin Sonjit ${ }^{a *}$, Nicholas Dacre ${ }^{a}, \&$ David Baxter ${ }^{a}$
}

\author{
${ }^{a}$ University of Southampton Business School, University of Southampton, Southampton, SO17 1BJ, UK \\ * Corresponding Author: p.sonjit@soton.ac.uk
}

\begin{abstract}
The Covid-19 global pandemic crisis has had a deep and profound impact on fundamental elements of society, the economy, and the environment as a whole. Key organisations, businesses, sectors and industries vital for delivering crucial projects have been affected by the relatively fast onset of Covid19 on a global scale. As a result, organisational routines and project management processes that would have focused on established methods and practices have incurred dramatic changes leading to a greater emphasis on agility as part of a more exhaustive strategic Covid-19 world, where new routines and processes become embedded as the new normal. This research focuses on the increased demand in Homeworking Project Management (HPM) and more significant agility requirements across dispersed virtual project management teams. Initial insights from semi-structured interviews with a crosssection of 12 high-level project professionals suggest that; (i) Transitional homeworking project management processes have a direct impact on collaborative and operational routines; (ii) There is a greater level of demand on agility with HPM teams which do not necessarily have the organisational infrastructure to support these, (iii) Technological resources are becoming a primary concern with inequality of information across HPM teams, and (iv) Increasing critical bottlenecks across dispersed HPM teams is adversely affecting tenable project outcomes.
\end{abstract}

Keywords: Project Management, Homeworking, Agility, Covid-19, HPM.

\section{Citation}

Sonjit, P., Dacre, N., \& Baxter, D. (2021). Homeworking Project Management \& Agility as the New Normal in a Covid-19 World. Advanced Project Management, 21(5). https://dx.doi.org/10.2139/ssrn.3823901

\section{Introduction}

In late 2019 and early 2020, the outbreak of the Covid-19 virus exposed organisations and project managers to a dramatic rise in the use of teleworking technologies. To help prevent the spread of infectious disease, teleworking technologies (i.e., e-mail, video conference software, telephone etc.) became practical tools that allow project team members to work at home to follow the self-isolation measure.

$20 \%$ of the employees have shifted to work from home since they have been unable to operate as expected in their workplace following socialdistancing standards (Ollo-López et al., 2020). Therefore, many businesses and organisations have been primarily affected because of employees' absence due to lockdown restrictions. Most project teams have had to adopt homeworking strategies, with parent organisations inevitably transitioning to new patterns to decrease general social health concerns. We refer to this phenomenon in this research as Homeworking Project Management (HPM). 
HPM is increasingly being recognised as a business solution that enables project professionals to work safely and maintain business continuity throughout the pandemic with the least harmful consequences towards the economy (Belzunegui-Eraso \& ErroGarcés, 2020; Papagiannidis et al., 2020).

Since the 1980s, the concept of homeworking has been increasingly embraced by many organisations in the UK according to the growing number of homeworkers which has nearly doubled from 345,920 to 680,6122 (Crosbie \& Moore, 2004) offering resilience in work schedule, work autonomy for employees, and influencing innovation capabilities (Baxter \& Taylor, 2019). However, previous iterations of this, such as teleworking practices, have been used dynamically across organisations with project teams working remotely. In contrast, the current instantiation arguably departs from prior approaches from a flexible to an enforced doctrine (Khahro et al., 2020).

HPM teams with little to no prior experience of homeworking practices are likely to receive high impact Covid-19 remote working challenges. Moreover, organisations tend to focus more on organisational processes to mitigate conflicts between remote working and organisational structures, such as inert decision-making resulting from bureaucratic systems (Dirani et al., 2020).

As such, there is increasing widespread disruption across established on-site project team management practices, which are experiencing disruptive changes due to the Covid-19 social distancing rules. To continually operate projects, organisations have to execute a disruptive transition in their processes and routines (Dacre et al, 2014) by running homeworking practices to prevent the spread of coronavirus and comply with the Covid-19 lockdown policy (OlloLópez et al., 2020).

HPM is increasingly establishing itself as the primary approach in mitigating the risk of infection in the workplace, as such project teams are required to adapt to change resulting from traditional managerial attitudes concerned with loss of direct control over homeworkers, developed before implementing telework (Belzunegui-Eraso \& ErroGarcés, 2020; Papagiannidis et al., 2020). Thus, leadership transformation is considered to be crucial for the project managers in the era of the Covid-19 crisis as it is an essential skill to effectively manage the project teams to continue to work effectively during the pandemic (Khahro et al., 2020).

To fully transform traditional project management teams to HPM within a short period requires vast amounts of effort both from the organisations and the project teams, such as developing work experience in primitive stages of homeworking (Tietze \& Nadin, 2011). Moreover, such transformation can negatively impact employee productivity and well-being if their jobs contain some tasks that need to be done physically, such as manufacturing and construction projects (Papagiannidis et al., 2020).

Project teams are inevitably faced with responding to the Covid-19 crisis. Therefore this research identifies this matter as a research gap aiming to explore further HPM challenges currently faced by virtual project teams and future aspects across various industries. In achieving this aim, this study adopts qualitative research (Reynolds \& Dacre, 2019) to explore the HPM challenges through a series of individual semi-structured interviews with a crosssection of high-level project professionals to extract in-depth information belonging to participants' experiences and perspective of a specific topic (Turner, 2010).

\section{Homeworking Project Management Challenges}

Prior research undertaken by Waizenegger et al., (2020) suggests that even though the homeworkers can manage their tasks and schedules flexibly, many of them who have been forced to implement the homeworking scheme will pose different challenges as they often share their workspace with other members of their family, leading to multiple distractions and less productivity when collaborating in teams.

The conflict between work and family is likely to cause employees' exhaustion which could drain their physical energy and harm their mental health while working from home (Golden, 2012). Moreover, it is difficult to manipulate and control, especially for employees living with children at home. Taking care of children is considered a burden for many families because they have to raise and educate children during work hours (Power, 2020). 
Yordanova (2015) revealed that women teleworkers in Bulgaria who have children are likely to work for 36 hours on average, which is higher than the average work hours of women without children for nearly 4 hours. Her study ascertained that women with children are expected to manage housework, raise children, and take care of family members' health as reasons for increasing work hours. Thus, household chores and child care are likely to encroach on the employee's time, leading to working overtime (Power, 2020).

Additionally, employees tend to feel more stress and uncertainty when overwhelmed (Dacre et al., 2019) by the expectation of remote working during lockdown when coupled with family responsibilities (Bartsch et al., 2020). To minimise conflicting work and family demands, increasing job autonomy could be a promising way to alleviate family-related challenges by offering the employees opportunity to manage their work hours for childcare support and other family responsibilities (Donthu \& Gustafsson, 2020; Wattoo et al., 2020).

Moreover, in times of Covid-19 there is evidence that suggests it is challenging for employees to manage their work-life balance while performing full-time home-based telework. Employees are likely to work longer hours compared to the pre-Covid19 period to address challenges induced by the Covid-19 crisis, and they had to spend extra hours operating to overcome specific organisational challenges, such as a surge in production demand and the absence of other employees due to illness (Nawrot, 2020).

During the pre-Covid-19 crisis, the demands on household responsibilities and working parents are already intense and overwhelming. The majority of these responsibilities generally fall on female professionals rather than males, highlighting an essential degree of gender inequality in homeworking (Power, 2020).

Moreover, working from home could result in the blurring of work-life boundaries and role conflict, which subsequently cause problems in family relationships (Crosbie \& Moore, 2004; Sull et al., 2020). For some homeworkers, personal time became scattered, but this issue rarely happens to the young professions who have no responsibility to take care of children (Crosbie \& Moore, 2004).
In a crisis, the level of tension in project teams is relatively high because the team members have to face several challenges under the virtual settings, such as role ambiguity, work conflicts, task overload, the lack of team motivation and uncooperative team members (Bartsch et al., 2020). In order to reduce the stress levels, the project team leaders are required to have the willingness to accelerate the necessary adaptive work, which will control the stress they experience themselves, and that everyone else feels as well (Fernandez \& Shaw, 2020).

Thus, project managers have to transform their management approach differs from that of co-located teams to cope with communication issues, limited visibility issues, coordination issues, and cooperation issues in the virtual team setting (Casey, 2010). Moreover, the organisation's capacity, such as the structure of operations, teleworking technologies, communication channel and the suitable organisational culture, is also necessary to be developed to underpin the transition from officebased to virtual-based work (Zuofa \& Ochieng, 2017).

\section{Methodology}

This research has, to date, conducted 12 interviews with a cross-section of high-level project professionals as part of a broader campaign to engage with 18 more to acquire enough data to sufficiently explain the phenomenon. Our participants are from diverse industries, such as aviation and aerospace, construction, IT, R\&D, Transportation, and Healthcare Consultation. The size of project teams ranges from 5 to 30 team members.

All interview sessions were conducted via online communication technology tools, such as Skype and Microsoft Teams to avoid physical contact and travel, with each session lasting between 40 and 60 minutes. The interviews were recorded using voice capture applications.

\section{Discussion \& Further Research}

At the human, systemic, societal, and global levels, the current COVID-19 crisis has, and will continue to have, a significant effect on us. Remote work and homeworking practice will likely remain in society and gradually bring new problems and challenges to project teams (Eggleton et al., 2020). Furthermore, the aftermath of the Covid-19 crisis will impact 
employment in the future as it will result in significant changes in the trends in labour markets and the required skills for the future workers will also shift due to the changing work patterns (Dacre et al., 2019; PwC, 2020). The demand for project managers who have digital skills (Brookes et al., 2020; Dacre et al., 2019, 2020; Hsu et al., 2021), agility skills (Dong et al., 2021), data skills (Kockum \& Dacre, 2021), communication skills, and leadership skills (Tite et al., 2021), will be more likely to be required since there is a possibility that organisations will require a more significant number of employees to implement remote working as the new normal.

More specifically, our initial findings suggest that; (i) Transitional HPM - Transitional homeworking project management processes have a direct impact on collaborative and operational routines; (ii) Increasing agility requirements - There is a greater level of demand on agility with HPM teams which do not necessarily have the organisational infrastructure to support these; (iii) Information inequality across IT platforms - Technological resources are becoming a primary concern with inequality of information across HPM teams; and (iv) Tenable project outcomes - Increasing acute bottlenecks across dispersed HPM teams is adversely affecting tenable project outcomes.

As part of a more comprehensive research investigation, we will further examine and explore these emergent topics to attribute these to developing a research framework to help guide current research exploration and contribute to project management practice. As these represent early findings, we also acknowledge that other themes may also emerge by revisiting and addressing these initial insights.

\section{References}

Bartsch, S., Weber, E., Büttgen, M., \& Huber, A. (2020). Leadership matters in crisis-induced digital transformation: How to lead service employees effectively during the COVID-19 pandemic'. Journal of Service Management. https://doi.org/10.1108/JOSM-05-20200160

Baxter, D., \& Taylor, R. (2019). How Telework Influences Innovation Capability: An Empirical Study. R\&D Management Conference, Paris, France.

Belzunegui-Eraso, A., \& Erro-Garcés, A. (2020). Teleworking in the Context of the Covid-19 Crisis'. Sustainability, 12(9), 3662.

https://doi.org/10.3390/su12093662
Brookes, N., Lattuf Flores, L., Dyer, R., Stewart, I., Wang, K., \& Dacre, N. (2020). Project Data Analytics: The State of the Art and Science [APM Research]. Association for Project Management.

https://doi.org/10.5281/zenodo.4621177

Casey, V. (2010). Virtual software team project management'. Journal of the Brazilian Computer Society, 16(2), 83-96. https://doi.org/10.1007/s13173-010-0013-3

Crosbie, T., \& Moore, J. (2004). Work-life balance and working from home'. Social Policy and Society, 3(3), 223233. https://doi.org/10.1017/S1474746404001733

Dacre, N., Constantinides, P., \& Nandhakumar, J. (2014). Instantiation of Organisational Routines in CrossExpertise Collaborative Enterprise Systems.

International Symposium on Process Organization Studies, Rhodes, Greece.

https://dx.doi.org/10.2139/ssrn.3829127

Dacre, N., Kockum, F., \& Senyo, PK. (2020). Transient Information Adaptation of Artificial Intelligence: Towards Sustainable Data Processes in Complex Projects. British Academy of Management, Manchester, UK. https://dx.doi.org/10.2139/ssrn.3813559

Dacre, N., Senyo, PK., \& Reynolds, D. (2019). Is an Engineering Project Management Degree Worth it? Developing Agile Digital Skills for Future Practice. Engineering Education Research Network, Coventry, UK. https://dx.doi.org/10.2139/ssrn.3812764

Dirani, M. K., Abadi, M., Alizadeh, A., Barhate, B., Garza, C. R., Gunasekara, N., Ibrahim, G., \& Majzun, Z. (2020). Leadership competencies and the essential role of human resource development in times of crisis: A response to Covid-19 pandemic'. Human Resource Development International, 23(4), 380-394.

Dong, H., Dacre, N., \& Bailey, A. (2021). Sustainable Agile Project Management in Complex Agriculture Projects: An Institutional Theory Perspective. Advanced Project Management, 21(3).

https://dx.doi.org/10.2139/ssrn.3829912

Donthu, N., \& Gustafsson, A. (2020). Effects of COVID-19 on business and research'. Journal of Business Research, 117, 284-289.

https://doi.org/10.1016/j.jbusres.2020.06.008

Eggleton, D., Dacre, N., Cantone, B., \& Gkogkidis, V. (2020). Redefining Success in Project Management [APM Research]. Association for Project Management. https://doi.org/10.5281/zenodo.4624779

Fernandez, A. A., \& Shaw, P. G. (2020). Academic leadership in a time of crisis: The Coronavirus and Covid19'. Journal of Leadership Studies, 14(1), 39-45. 
Golden, D. T. (2012). Altering the Effects of Work and Family Conflict on Exhaustion: Telework During Traditional and Nontraditional Work Hours'. Journal of Business and Psychology, 27, 255-269.

https://doi.org/10.1007/s10869-011-9247-0

Hsu, MW., Dacre, N., \& Senyo, PK. (2021). Applied Algorithmic Machine Learning for Intelligent Project Prediction: Towards an AI Framework of Project Success. Advanced Project Management, 21(4).

https://dx.doi.org/10.2139/ssrn.3823900

Khahro, S. H., Ali, H. T., A., V. A., Khahro, Q. H., \& Moriyani, M. A. (2020). Post Pandemic Project Management Key Skills and Challenges'. Journal of Talent Development \& Excellence, 12(3), 2253-2260.

Kockum, F., \& Dacre, N. (2021). Project Management Volume, Velocity, Variety: A Big Data Dynamics Approach. Advanced Project Management, 21(1). https://dx.doi.org/10.2139/ssrn.3813838

Nawrot, W. (2020). Mitigating risk of negative productivity shock in the post Covid-19 normalisation phase (P. Bunkanwanicha, R. rCoeurderoy, \& S. B. Slimane, Eds.).

Ollo-López, A., Goñi-Legaz, S., \& Erro-Garcés, A. (2020). Home-based telework: Usefulness and facilitators'. International Journal of Manpower. https://doi.org/10.1108/IJM-02-2020-0062

Papagiannidis, S., Harris, J., \& Morton, D. (2020). WHO led the digital transformation of your company? A reflection of IT related challenges during the pandemic'. International Journal of Information Management. https://doi.org/10.1016/j.ijinfomgt.2020.102166

Power, K. (2020). The COVID-19 pandemic has increased the care burden of women and families'. Sustainability: Science, Practice and Policy, 16(1), 67-73.

PwC. (2020). UK Economic Update', United Kingdom: PwC. https://www.pwc.co.uk/premium/covid-19/ukeconomic-update-covid-19.pdf
Reynolds, D., \& Dacre, N. (2019). Interdisciplinary Research Methodologies in Engineering Education Research. Engineering Education Research Network, Coventry, UK. https://dx.doi.org/10.2139/ssrn.3812769

Sull, D., Sull, C., \& Bersin, J. (2020). Five Ways Leaders Can Support Remote Work'. MIT Sloan Management Review, 61(4), 1-10.

Tietze, S., \& Nadin, S. (2011). The psychological contract and the transition from office-based to home-based work'. Human Resource Management Journal, 21(3), 318-334. https://doi.org/10.1111/j.1748-8583.2010.00137.x

Tite, C. N. J., Pontin, D., \& Dacre, N. (2021). Embedding Sustainability in Complex Projects: A Pedagogic Practice Simulation Approach. Advanced Project Management, 21(2). https://dx.doi.org/10.2139/ssrn.3814008

Turner, W. D. (2010). Qualitative interview design: A practical guide for novice investigators'. The Qualitative Report, 15(3), 754-760.

Waizenegger, L., McKenna, B., Cai, W., \& Bendz, T. (2020). An affordance perspective of team collaboration and enforced working from home during COVID-19'. European Journal of Information Systems. https://doi.org/10.1080/0960085X.2020.1800417

Wattoo, A. M., Zhao, S., \& Xi, M. (2020). Highperformance work systems and work- family interface: Job autonomy and self-efficacy as mediators'. Asia Pacific Journal of Human Resources, 58(2020), 128-148. https://doi.org/10.1111/1744-7941.12231

Yordanova, G. (2015). Global Digital Workplace as an Opportunity for Bulgarian Woman to Achieve WorkFamily Balance'. The Dynamics of Virtual Work, 5, 1-12.

Zuofa, T., \& Ochieng, E. G. (2017). Working separately but together: Appraising virtual project team challenges'. Team Performance Management, 23(5-6), 227-242.

Advanced Project Management | APROM www.southampton.ac.uk/aprom

The Advanced Project Management research series accepts working conceptual and empirical papers, literature reviews, development papers, technical papers, case studies, and general reviews. Papers of a qualitative, quantitative, or mixed methods nature are welcome, including highly novel research approaches where relevant. Authors retain copyright of their work. The title page should include: Title; Author Name(s); Institution Affiliation(s); Contact Email Address(es); Abstract; and Keywords. Submit your paper as a Word or PDF file to: aprom@southampton.ac.uk 